\title{
Bibliografía complementaria
}

Juan Helguera, Nicolás García Tapia y Fernando Molinero: El canal de Castilla, Junta de Castilla y León, Valladolid, 1988. Andrés Llaurado y Fábregas: La navigation intérieure en Espagne. IVe congrès international de navigation intérieure, Manchester, 1890.

Felipe Mora: Canalización del Manzanares, Jarama y Tajo para la navegación entre Madrid y Lisboa, Madrid, 1909.

David R. Ringrose: Los transportes y el estancamiento económico de España (1750-1850), Madrid, 1972.

Francisco Xavier de Cabanés: Memoria que tiene por objeto manifestar la posibilidad y facilidad de hacer navegable el río Tajo desde Aranjuez hasta el Atlántico, Madrid, 1829.

\section{NUEVOS HALLAZGOS ROMÁNICOS EN EL MONASTERIO DE SAN ZOILO DE CARRIÓN DE LOS CONDES (PALENCIA) ${ }^{1}$.}

En el mes de octubre de 1999 y durante unos trabajos en la iglesia barroca del que fuera priorato cluniacense y monasterio benedictino de San Zoilo de Carrión de los Condes, aparecieron diversos restos románicos que se añaden al espectacular descubrimiento de la portada occidental cuya valoración fue publicada en esta misma revista ${ }^{2}$.

Desde aquellas fechas se ha podido avanzar de modo considerable en el conocimiento de la realidad material de la desaparecida iglesia románica, cuestión sobre la que se continúa trabajando ${ }^{3}$. Sabemos que era un edificio de planta basilical, de tres naves, cada una de ellas con cuatro tramos, y un transepto no destacado en planta cuyo tramo de crucero muy probablemente fue coronado por un cimborrio. Asimismo fue dotada de una elaborada fachada occidental con dos torres que albergaba el panteón funerario de la poderosa familia Banu-Gómez de $\mathrm{Ca}$ rrión, espacio polivalente denominado con el ambiguo término de galilea.

Los trabajos de desenfoscado han puesto a la luz una buena parte del muro meridional románico reutilizado hasta el mismo arranque de la bóveda de cañón que cubría la nave de la Epístola del templo. Su exterior fue forrado a fines del siglo xvi por la obra del nuevo claustro proyectado por Juan de Badajoz. Asimismo es visible buena parte del paramento septentrional ampliamente destruido al llevarse a cabo la gran portada barroca. Como era frecuente, a la hora de sustituir su vieja construcción románica, la comunidad benedictina carrionesa se rigió por un criterio esencialmente económico. De este modo la traza barroca contempló el máximo aprovechamiento del encintado mural del templo precedente, limitándose a derribar los intercolumnios, a tabicar ventanas y afeitar impostas, fustes y capiteles de los muros. Sabemos que los trabajos se extendieron a lo largo de buena parte del siglo xvII y que, como resultaba frecuente, la primitiva traza del edificio se fue desvirtuando (prescindencia de una segunda y es-

\footnotetext{
1 Con posterioridad a la entrega al consejo de redacción de $A E A$, este trabajo fue ampliado en la ponencia: «La sculpture des royaumes chrétiens du Nord-Ouest de la Péninsule Ibérique vers l'an 1100: la captation d'un modèle de portail monumental», Colloque International à l'occasion du 9ème centenaire du clôttre de Moissac (Moissac, 28-30 juin 2000).

${ }^{2}$ José Luis Senra: «La portada occidental recientemente descubierta en el monasterio de San Zoilo de Carrión de los Condes», Archivo Español de Arte, LXVII (1994), pp. 57-72.

${ }^{3}$ José Luis Senra: «Algunas notas sobre la desaparecida iglesia románica del priorato cluniacense de Carrión de los Condes», en: III Congreso de Historia de Palencia (Palencia 30-31 de marzo y 1 de abril de 1995), Palencia 1996, tomo IV, pp. 439-451. También: «Aproximación a los espacios litúrgico-funerarios en Castilla y León: pórticos y galileas», Gesta, XXXVI/2 (1997), pp. 122-144; «Estructuras occidentales en los reinos occidentales de la Península Ibérica», en: Les avant-nefs et les espaces d'accueil dans l'église entre le Ive et le xlle siècle (Colloque International, Auxerre, 17-20 juin 1999) [Actas en prensa].
} 
paciosa sacristía al Norte) hasta ofrecer el poco afortunado resultado que hoy contemplamos. Además al alto coste que suponía la utilización de sillería se sumaban los elevados gastos derivados de su transporte - no hay que olvidar que la piedra es un material escaso en territorio de Campos- lo que motivó un aprovechamiento máximo del sillar románico y la masiva utilización de ladrillo.

Se trata de dos capiteles ubicados en las que fueron columnas de separación entre los tramos primero y segundo (contabilizando desde la cabecera) de las naves laterales. Hasta su descubrimiento permanecieron emparedados por los grandes pilares contiguos al tramo del actual crucero. Los cimacios $(0,16)$ se decoran con palmetas inscritas en tallos muy próximos a las que presenta el capitel de la vendimia de la portada occidental. En cuanto a las dos cestas, ambas de considerable amplitud $(0,70)$, la correspondiente al muro del Evangelio se ornamenta con un complejo entrelazo que fue mutilado en el momento de ser adosado el pilar barroco contiguo. Por el contrario, la del lado meridional lo hace con un enrevesado motivo figurado. En ambos ejemplares las volutas que han subsistido se abren completamente sobre el plano de la cesta.

El capitel figurado, de evidente mayor interés, responde a una estilística que, sin ningún género de duda, entronca directamente con las realizaciones de la portada románica occidental (fig. 1). Al acusado sentido del volumen que presenta este grupo escultórico se suman nítidas convergencias en el léxico. Una vez más se aprecian dos variantes en el tratamiento de los pliegues de las vestimentas: el entablillado y el tubular. Asimismo en los rasgos faciales destaca el leve prognatismo y el tenue rasgado de ojos con párpados marcados y ausencia de pupilas. Responden también al mismo hacer los cabellos trenzados con una característica melena recogida. Hay una atracción por ciertos detalles anatómicos como puede apreciarse en rasgo tan evidente como es el marcado de las uñas de los pies o en la definición de garras. En lo que se refiere a los pliegues tubulares, ya se hizo alusión a las figuras de la lauda del hijo de Pedro Ansúrez, Alfonso († 1093) y, en un estadio más evolucionado, en los personajes del relieve de la fachada del Cordero en San Isidoro de León ${ }^{4}$. También enlazan con las figuras del sepulcro los bocamangas y cuellos ornados a base de rombos concatenados, presentes en los personajes de este capitel aunque no en los de la portada occidental. Sin embargo persiste la limitación de conexiones plásticas con las realizaciones de la vecina iglesia de San Martín de Frómista (dependiente de San Zoilo a partir de 1118), tan sólo perceptibles en algunos de los capiteles de la cabecera. Asimismo es notoria la ausencia del espíritu antiquizante presente en esa zona del templo de San Martín y abiertamente desplegado en la catedral de Jaca.

En lo tocante a la composición de la cesta, tal y como se ha dicho, tan solo son visibles la cara lateral derecha y buena parte de la frontal, quedando totalmente oculta la izquierda. Se articula mediante un esquema centrífugo aunque no completamente simétrico. La frontal está dominada por un león con una elegante disposición de los cuartos delanteros, cruzados, en disposición de avanzar, y cuya cabeza converge en el ángulo derecho. En este lugar un personaje barbado, vestido con camisa y falda corta, y cuyo cuerpo ocupa parte de la cara derecha, aferra con ambos brazos la cabeza del animal mostrando sus amenazadoras fauces. Sobre el lomo del león se encaraman dos pequeñas aves acoladas, de poderosas garras (presumiblemente águilas) que pueden verse con dificultad. Las colas se unen en las fauces de otra cabeza leonina, de menor tamaño y que ocupa la parte superior del eje de la cara mayor de la cesta. Finalmente, en el espacio de la cara derecha no ocupada por el personaje barbado, aparece una figura masculina ataviada con toga, prenda que recoge con la mano izquierda, calzada y portando un libro en su mano derecha.

\footnotetext{
${ }^{4}$ José Luis Senra: «La portada occidental recientemente descubierta ...», p. 69.
} 
Este complejo iconograma encuentra un paralelo que se ha conservado en uno de los capiteles de la catedral de Jaca (cara occidental del pilar toral suroeste) lugar del que parece que se derivó a dos de los ejemplares de la iglesia superior del castillo de Loarre (pilares noreste y noroeste) (figs.2-3) ${ }^{5}$. Una vez más la catedral aragonesa se convierte en referente iconográfico para San Zoilo: como se sabe, en la portada occidental palentina aparece el episodio veterotestamentario de la 'Burra de Balaam', presente también en el acceso meridional del templo jacetano (capitel izquierdo $)^{6}$. La diferencia más notable entre los capiteles aragoneses y el de Carrión se centra en lo que parecen tres licencias del escultor de este último: el rostro barbado de al menos uno de los personajes que sujetan a los leones de ángulo y en lo que pudiera ser una inversión de figuras en las caras menores. En la cara derecha aquellos insertan figuras desnudas mientras que en San Zoilo vemos la figura vestida con túnica. Además este personaje aparece claramente desvinculado de la escena: no aferra el brazo de la figura barbada del ángulo sino que sustenta un libro. Es muy probable que en la cara izquierda, oculta, se encuentre una figura masculina desnuda.

Existe un completo desconocimiento en torno a su particular temática. Ya Manuel Gómez Moreno hizo una alusión genérica a los capiteles de la seo aragonesa en los que aparecían muchachos desquijarando leones, «como recuerdo de la hazaña de Sansón, asunto muy favorecido entre nuestros escultores románicos» ${ }^{7}$. Por otra parte fue quien primero llamó la atención sobre la complejidad iconográfica de este ejemplar así como de su fiel reproducción en la iglesia del castillo de Loarre ${ }^{8}$. Mucho más recientemente Marcel Durliat ha apuntado la existencia de una tosca cesta descontextualizada de la catedral de Santa María del Popolo de Pavía, que se conserva en el Musei Civici de esa ciudad, con esta misma iconografía (inv. B-60) (fig. 4) ${ }^{9}$. Datada a fines del siglo XI o comienzos del XII y mutilada en su parte izquierda, las diferencias son fundamentalmente de orden compositivo ${ }^{10}$. Al igual que ocurre con Jaca, Loarre y Carrión, resulta imposible precisar el grado de afinidad de este capitel italiano respecto al hipotético prototipo de ese críptico iconograma. Es evidente que presenta un equilibrio de composición superior que el de aquellos tres, fundamentado en la representación simétrica, en su cara frontal, mediante dos leones de cuerpo entero contrapuestos y sentados sobre su cuartos traseros. Encima de ellos, pero no sobre sus lomos tal como aparecen en los ejemplos hispanos, se disponen dos aves cuyas respectivas colas convergen en la boca de una cabeza animal desauriculada que surge en la parte superior del eje de la cesta. Ambas introducen sus picos en las bocas

\footnotetext{
${ }^{5}$ Sobre las copias en este contexto ver: Serafín Moralejo: «Modelo, copia y originalidad, en el marco de las relaciones artísticas hispano-francesas (siglos XI-XIII)», en: Vè Congrés Espanyol d'Història de l'Art (Barcelona, 29 d'octubre al 3 de novembre de 1984), Barcelona 1986, vol. I, pp. 89-112.

${ }^{6}$ José Luis Senra: «La portada occidental recientemente descubierta ...», pp. 62-63, figs.7-8. En su momento ya se refirieron las diferencias de composición respecto al ejemplar existente en el panteón de San Isidoro (id., 62, n.15).

${ }^{7}$ Manuel Gómez Moreno: El arte románico español. Esquema de un libro, Madrid 1934, p. 73, lám. LXXXVI. Una variante de esta temática aparece en el capitel de doble columna correspondiente al pilar toral noroeste de la catedral.

${ }^{8}$ Gomez Moreno (1934): 80, lám.XLIII. También: Georges Gaillard: Les débuts de la sculpture romane espagnole: León, Jaca et Compostelle, Paris 1938, pp. 103-104, pl. XLIV, figs. 23-23 bis. Angel Canellas López y Angel San Vicente ya señalaron la diferencia de este capitel respecto al jaqués en el tratamiento del relieve y de las formas (Aragón [Vol. 4 de la serie «La España Románica»], Madrid 1979 (La Pierre-qui-Vire 1971), p. 176). Más recientemente Janie Mann resulta algo ambigua en su opinión concerniente al papel de modelo iconográfico presuntamente ejercido por Jaca respecto a Loarre (Janie Elaine Mann: San Pedro at the Castle of Loarre, a Study in the Relation of Cultural Forces to the Design, Decoration and Construction of a Romanesque Church, Ph. D. dissertation. New York (Columbia University), 1991, pp. 134-139).

${ }^{9}$ Marcel Durliat: La sculpture romane de la route de Saint-Jacques. De Conques à Compostelle, Mont-de-Marsan 1990, p. 234. Ver también: «La sculpture romane de la cathédrale de Jaca», Cahiers de Saint-Michel de Cuxa, 10 (1979), pp. 9799. También: Marcel Durliat: «Les origines de la sculpture romane à Jaca», Académie des Inscriptions et Belles-Lettres, 1978, p. 372.

${ }^{10}$ Adriano Peroni: Pavia. Musei Civici del Castello Visconte, Bologne 1975, p. 39-40 n. ${ }^{\circ} 178$. Agradezco a Saverio Lomartire y a Manuel Castiñeiras sus respectivas gestiones para la obtención de la fotografía adjunta.
} 

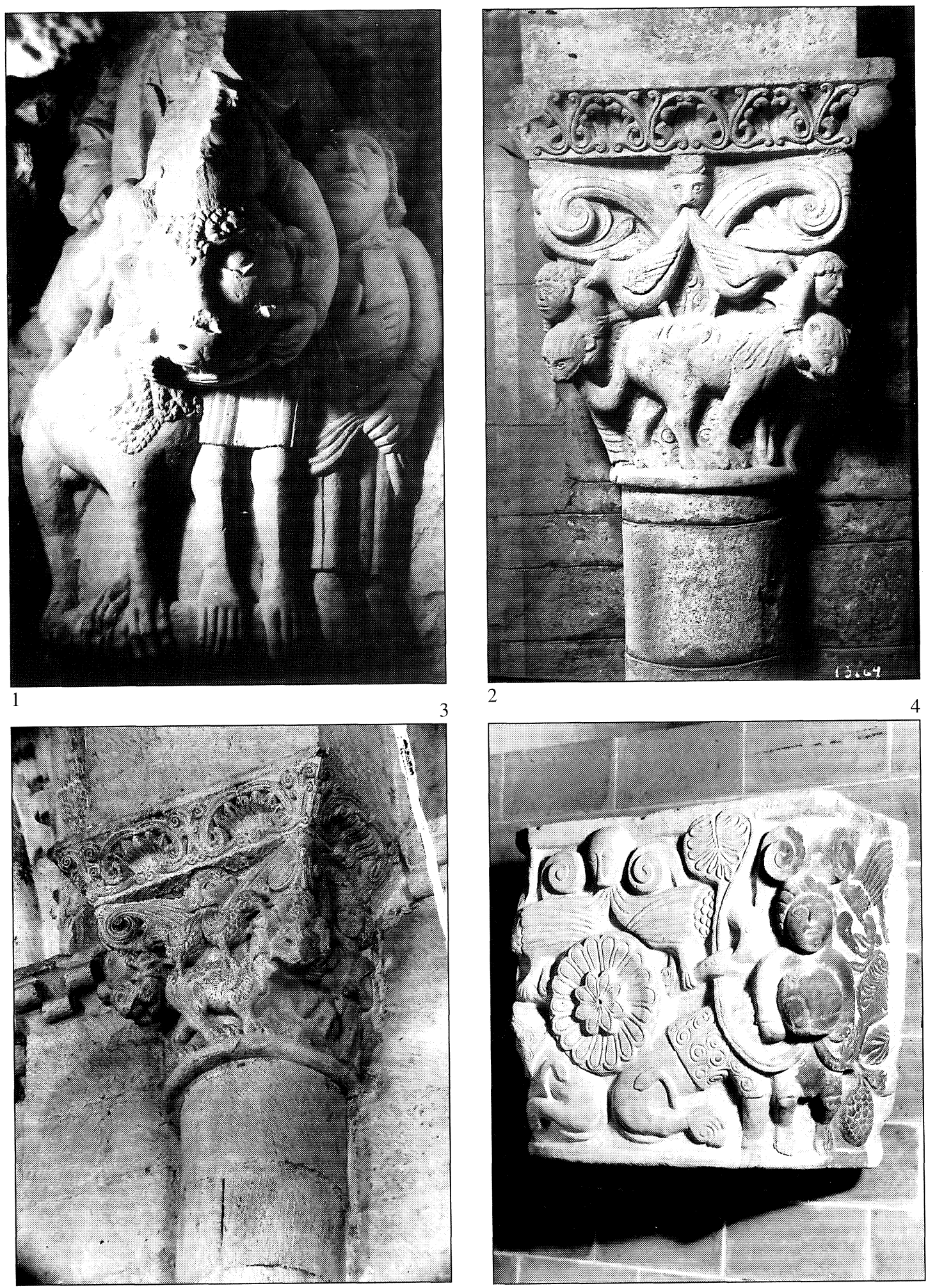

Fig. 1. Capitel de la iglesia de San Zoilo de Carrión (Palencia) [Foto: autor].

Fig. 2. Capitel de la catedral de Jaca (Huesca) [Foto: Moreno. Madrid].

Fig. 3. Capitel de la iglesia del castillo de Loarre (Huesca) [Foto: Insdtitut Amatller d'Art Hispanic]

Fig. 4. Capitel de la catedral de Santa María del Popolo. Pavía [Foto: Musei Civici. Pavia]. 
de sendas serpientes. Dos personajes esquinados abren las fauces de los leones de las que surgen tallos vegetales. En el centro de la cara mayor, concretamente en el espacio restante entre águilas y leones, se inserta un gran florón ${ }^{11}$.

Aunque hemos perdido la formulación del mensaje de estos tres capiteles, al menos pueden trazarse algunas líneas de aproximación al hermético código desplegado en ellos. Como es sabido, desde San Agustín el león no ha sido ajeno a la ambivalencia de la simbología animal. Por un lado es una tradicional evocación cristológica; por otro se identifica con el diablo o, genéricamente, con la muerte ${ }^{12}$. A este respecto, los textos bíblicos son del todo expresivos:

«Mas tú, Yavé, no estés lejos, joh fuerza mía, vuela en mi socorro! Libra mi alma de la espada, de las garras del perro mi alma única. Sálvame de las fauces del león, de los cuernos del toro mi vileza» (Salmos, 22 [21]: 20-22).

«iSed sobrios y estad en guardia! Vuestro enemigo el diablo, como león rugiente, da vueltas y busca a quién devorar» (Primera carta de San Pedro, 1, 5, 8) ${ }^{13}$.

Por otra parte el águila, más allá del tradicional símbolo de Juan el Evangelista según la visión de Ezequiel, es convertida en la alegoría de la inmortalidad a través de la redención (Salmos, 103 [102]: 5) ${ }^{14}$. Y en la imaginería medieval, la antitética relación del león con el águila resulta relativamente común ${ }^{15}$. En este grupo de capiteles que nos ocupan, las figuras de ángulo que muestran las fauces leoninas podrían considerarse meros comparsas pero cuestión más compleja parece la definición del papel desempeñado por al menos dos de los personajes de las caras laterales. Como ya señalamos, en San Zoilo el único visible (cara derecha) se desvincula de las escenas de ángulo (no aferra el brazo más próximo de la figura barbada) e introduce un libro, motivo netamente apocalíptico, rasgo que anima a su identificación con San Juan ${ }^{16}$. No es posible contemplar la cara izquierda pero hay que reseñar la identificación de las figuras desnudas de los ejemplares aragoneses con la imagen de Hércules victorioso ataviado con la piel del león de Nemea sobre la cabeza y portando la clava (más evidente en el capitel NE de Loarre). Como es bien sabido la representación de este héroe clásico de esta

1 La composición con una figura humana mostrando las fauces de un león es un motivo muy frecuente en la iconografía del románico. En esta misma área geográfica e idéntico segmento cronológico la presencia de leones con una carga simbólica negativa está muy presente en la iglesia monástica de San Pedro de las Dueñas (León) [leones andrófagos] o en uno de los capiteles del primer proyecto de la iglesia de San Isidoro de León (c. 1100). Concretamente en el ejemplar insertado en la cara occidental del pilar toral del lado del Evangelio que representa abiertamente a un Sansón, con su cabello trenzado, desquijarando al león de Timna (Marcel Durliat: La sculpture romane ..., p. 370, fig. 391) si bien en su composición se aleja considerablemente de los esquemas tanto jaqués como palentino. Con este último encuentran mayor afinidad los leones de las caras laterales de Carrión.

12 Sobre este asunto, Antonio Quacquarelli: Il leone e il drago nella simbolica dell'età patristica, Bari 1975, pp. 19-37. También: Santiago Sebastián, El fisiólogo atribuido a San Epifanio seguido de El Bestiario toscano, Madrid 1986, pp. 315 (I), 21-22 (II).

${ }^{13}$ Cit. Moshe Barasch: «An Unknown Work of Medieval Sculpture in Acre». En: Imago Hominis. Studies in the Language of Art, Vienna 1991 (1972), pp. 223-224.

${ }_{14}$ Una síntesis en torno al origen simbólico del águila: Barasch, 1991 (1972): 226-228. También: Bianca \& Gustav Kühnel: «An Eagle Physiologus Legend on a Crusader Capital from Coenaculum», en: Norms and Variations in Art. Essays in Honour of Moshe Barash, Jerusalem 1983, pp. 38-40.

${ }^{15} \mathrm{La}$ contraposición de leones y águilas puede verse claramente en varios capiteles del siglo XII: Saint Aignand d'Échillais y Arces (Charente Maritime), Saint-Eutrope de Saintes (Saintonge) (V.-H. Debidour: Le bestiaire sculpté du Moyen Age en France, París 1961, figs.191-192, 194 y 224). Puede reseñarse también al menos un ejemplar perteneciente a época de los Cruzados en la mezquita de al-Aqsa (Jerusalén) (Barasch, 1991 (1972): 214; Kühnel (1983): 46, plate XI, fig.8). En el capitel de Pavía esta contraposición no es tan estrecha y ambos animales, también duplicados, configuran dos escenas. Como señalábamos, estas últimas aferran y picotean a sendas serpientes (nueva evocación de lo diabólico) y la unificación de escenas desde la óptica de la composición se realiza mediante tallos. Sobre el águila y la serpiente en época medieval ver: Rudolf Wittkower, «Eagle and Serpent: A Study in the Migration of Symbols», en: Allegory and the Migration of Symbols, Boulder 1977 (1938-39), pp. 31-39.

${ }^{16}$ Mientras que la representación de la figura calzada en principio dificulta su identificación con uno de los cuatro Evangelistas, la presencia del libro apunta en sentido afirmativo. 
manera resulta excepcional en la iconografía románica ${ }^{17}$. Hay que tener en cuenta que Hércules también fue envuelto con una dualidad simbólica en cuya traslación positiva, como prefiguración de Cristo liberador de los males del mundo y triunfador sobre la bestia, debería ser tomado en este marco iconográfico ${ }^{18}$. La incorporación de un personaje de la mitología clásica no puede sorprender en un área y en un tramo cronológico como este en el que tenemos consignada una verdadera fascinación de los escultores románicos por los sarcófagos antiguos ${ }^{19}$.

Pero al margen de todo lo dicho y regresando a las cuestiones estilísticas, creo que a partir de este capitel de San Zoilo y de los aparecidos hace algunos años en la portada occidental, es posible avanzar más en la filiación de al menos uno de los escultores que trabajó en la iglesia del priorato cluniacense de Carrión de los Condes. Para ello debemos acudir de nuevo a la escultura desplegada en la iglesia superior del castillo aragonés de Loarre ${ }^{20}$. Como es sabido allí trabajaron una serie de artesanos de la piedra de diversas direcciones estilísticas, algunas de ellas definidas desde hace tiempo por diferentes especialistas. Una esta inequivocamente emparentada con las realizaciones de la basílica de Saint-Sernin de Toulouse y del claustro de la abadía de Saint-Pierre de Moissac ${ }^{21}$. Otra puede rastrearse el algunos de los más antiguos capiteles de la iglesia de San Isidoro de León ${ }^{22}$. Otra, en fin, enlaza con lo que puede verse en el templo de San Juan de la Peña y con las realizaciones de la catedral de Jaca que parece haber sido el epicentro de una querencia estilística hacia lo tardorromano que se difundió hasta Compostela ${ }^{23}$. A esta última parece pertenecer el capitel del castillo oscense que reproduce el iconograma que aquí hemos tratado ${ }^{24}$. Sin embargo algunas otras esculturas no han encontrado filiación concreta. Y entre ellas nos interesa resaltar algunas de las cestas historiadas que ornamentan las ventanas del interior del hemiciclo absidal y del muro meridional. Representan te-

17 Lo excepcional de esta figura radica en que aparece siguiendo estrictamente la tradición mitológica, es decir, desnudo y con los atributos de la maza y la piel de león algo nada habitual durante la Edad Media (Erwin Panofsky / Fritz Saxl: La mythologie classique dans l'art médiéval, Brionne 1991 (New York 1933), pp. 8-12, 27-33; Erwin Panofsky: Hercule à la croisée des chemins et autres matériaux figuratifs de l'antiquité dans l'art plus récent, París 1999 (Leipzig/Berlín 1930), pp. 51-56).

${ }_{18}$ El conflictivo proceso de conciliación de ciertos personajes de la antigüedad pagana por parte de la patrística medieval ha sido subrayada por diferentes autores. La equiparación de Hércules con Sansón, si bien frecuente, no siempre fue fácil como ponen de relieve autores tan tempranos en el 'enfrentamiento' con la cultura clásica como Aldelmo de Malmesbury (ca. 639-709) (Erwin Panofsky: Renacimiento y renacimientos en el arte occidental, Madrid 1988 [Stockholm 1960], p. 87, n.4). Es un hecho que las connotaciones positivas del héroe coexistieron con su, por otro lado inevitable, papel como alegoría del vicio (Moshe Barash: «Le beau ou le démoniaque: le regard du spectateur médiéval sur la statuaire classique», en: Histoire de l'histoire de l'art. Tome I: De l'Antiquité au XVIIIe siècle, París 1995, pp. 105-106). En cualquier caso, la acomodación de los trabajos de Hércules no fue ajena a la iconografía cristiana (Walter Oakeshott: Classical Inspiration in Medieval Art, London 1959, p. 94). Pero en la representación estática e individualizada de Sansón-Hércules tampoco debe olvidarse la preferencia a este último a causa de la mayor nitidez de sus atributos (clava y piel de león) y, por tanto, de su más fácil identificación.

19 Sobre esta cuestión, Serafín Moralejo Alvarez: «Sobre la formación del estilo escultórico de Frómista y Jaca», en: Actas del XXIII Congreso Internacional de Historia del Arte. Granada 1973, Granada 1976, tomo I, pp. 427-434; «La reutilización e influencia de los sarcófagos antiguos en la España medieval», en: Colloquio sul reimpiego dei sarcofagi romani nel medioevo (Pisa 5-12 september 1982), Marburg/Lahn 1984, pp. 187-203. En torno a los trasvases de la antigüedad clásica al románico, Salvatore Settis: «Continuità, distanza, conoscenza. Tre usi dell'antico», en: Memoria dell'antico nell'arte italiana. III-Dalla tradizione all'archeologia. Torino 1986, pp. 373-486.

20 Ya fueron apuntadas las puntuales semejanzas compositivas de uno de los presumibles capiteles del desaparecido claustro románico de San Zoilo respecto a otro del hemiciclo del templo de Loarre (Senra (1994): 64).

${ }_{21}$ Gómez Moreno (1934): 80; Gaillard (1938): 138. Más recientemente: Serafín Moralejo: «Une sculpture du style de Bernard Gilduin à Jaca». Bulletin Monumental, 131 (1973), pp. 7-16. En torno a estos trasvases: Thomas W. Lyman: «Notes on the Porte Miègeville Capitals and the Construction of Saint-Sernin in Toulouse», The Art Bulletin, XLIX (1967), pp. 28 y 31, fig.18. Más recientemente: Serafín Moralejo: «Modelo, copia y originalidad ...» (1986), pp. 91-99.

22 Gaillard (1938): 139.

${ }^{23}$ Sobre la irradiación a Compostela ver: Serafín Moralejo, «La primitiva fachada norte de la catedral de Santiago», Compostellanum XIV (1969), pp. 664-666.

${ }^{24}$ Gaillard (1938): 141, pl. LXIV, 16. Sobre este capitel ver más recientemente: Marcel Durliat: La sculpture romane ... pp. 279-280. 
mas diversos algunos de ellos de significado indefinido: leones afrontados, personaje sustentando a un animal cuadrúpedo con una cuerda (claramente derivado de uno descontextualizado de la seo de Jaca, expuesto en el museo catedralicio), figuras desnudas cubriéndose con un manto, $\ldots{ }^{25}$ Un pausado análisis plástico de estos ejemplares nos remite sin demasiado esfuerzo al hacer de la escultura conservada en la iglesia de San Zoilo de Carrión, bien que en un estadio más inmaduro: los rasgos fisiognómicos y particularmente faciales, los cabellos trenzados con las melenas recogidas, las vestimentas resueltas con la mencionada combinación de tubos y tablillas, el detallismo de plasmar las uñas de los dedos, las cabezas de los leones, $\ldots{ }^{26}$.

Si nos atenemos a lo limitado de la producción de esta serie de capiteles de Loarre y a su propio destino, las ventanas, parece evidente que el papel desempeñado por este escultor en la iglesia de la fortaleza fue secundario. Sin embargo durante su permanencia en la obra coexistió con otros artesanos con los que pudo haber perfeccionado su oficio recogiendo además algunas composiciones iconográficas. En relación con este aspecto y ahondando en su inevitable permeabilidad, formando parte del equipo que produjo la escultura monumental de la iglesia del castillo aragonés, no debe ser casual la iconografía del capitel que acaba de ser hallado en el que fuera priorato cluniacense. Siguiendo esta hipótesis, muy probablemente el modelo seguido en Carrión sería el de Loarre, al igual que este último seguiría muy de cerca al que parece ser prototipo de esta área geográfica, el de Jaca. Es relevante el detalle del personaje de la cara lateral derecha de Carrión recogiéndose la toga con una mano al igual que ocurre con la figura de la cara izquierda del de Loarre, algo que sin embargo no ocurre en Jaca ${ }^{27}$. El alcance de este horizonte propuesto podría definirse con mayor rotundidad a través de una más que deseable intervención arqueológica en la iglesia de San Zoilo. Quizá entonces, con la más que probable aparición de fragmentos, podamos llegar a precisar, no sólo las incógnitas arquitectónicas del desaparecido edificio, sino también las ornamentales. Sabemos que la portada septentrional era el acceso principal al templo y es inevitable preguntarse como se configuraba. La tipología de portada incorporando un friso esculpido en su zona superior está presente en las dos iglesias románicas que han subsistido en Carrión: la de Santa María y la de Santiago. En este último caso con un Pantocrator y su Tetramorfos rodeado del colegio apostólico. Hace escasos años Marcel Durliat volvió a destacar la presencia de este nuevo elemento decorativo en la iglesia de Loarre en fechas prematuras -como se sabe muy mutilado- llamando la atención sobre su desarrollo en la región de Palencia durante la última fase del románico con ejemplos como el de Santiago de Carrión o el de Moarbes ${ }^{28}$. Teniendo en cuenta la filiación que

25 Marcel Durliat: La sculpture romane ..., pp. 277-279, figs. 273, 275 y 277. Este último parece reproducir el mismo iconograma que otro ubicado en el interior de una de las ventanas de la también iglesia oscense de Santa María de Iguacel (Marcel Durliat: La sculpture romane ..., p. 256, fig. 239).

${ }^{26}$ La agrupación estilística de los capiteles de Loarre propuesta por Janice Mann, a mi modo de ver, es discutible en algunos extremos que el limitado espacio de este artículo no permite concretar (Mann (1991): 264-274).

27 También conectan en la definición de los cuerpos de los personajes de ángulo que en Jaca se limitan a cabezas y brazos. Este rasgo, al que se suma un mayor desarrollo volumétrico, denota un avance muy notable del escultor de Carrión respecto a los aragoneses. Sin embargo diverge del ejemplar de Loarre en lo que se refiere el plumaje de las águilas: en el capitel de castillo las plumas cubren toda la superficie del cuerpo mientras que en San Zoilo, al igual que en Jaca, se circunscriben a las alas. Por otro lado, en Carrión no puede asegurarse nada de la cola del león de la cara frontal pero existen divergencias entre las dos cestas aragonesas: mientras en Jaca es mordida por la cabeza de león del ángulo izquierdo, en Loarre aparece entre las patas del animal.

${ }_{28}$ Marcel Durliat: La sculpture romane ..., p. 266. Serafín Moralejo propuso para este friso de Loarre una filiación estilística en torno a la irradiación del estilo de Bernard Gilduin («Une sculpture du style de Bernard Gilduin à Jaca», p. 14).

${ }_{29}$ Justamente, y desde el plano estrictamente arquitectónico, es significativa la elaboración que presenta el tramo occidental de la iglesia de Santiago dotado de un pórtico y una tribuna. Por otro lado, ya ha sido señalada la reelaboración iconográfica de uno de los capiteles de la portada de Santiago a partir de otro de la occidental de San Zoilo (José Luis Senra: «La portada occidental recientemente descubierta ...», p. 62).

30 «En el anno de MXCIIII» el rey Sancho Ramírez «hedificó el castiello de Marcuello et de Loarre et Alquezar» (Crónica de San Juan de la Peña (C. Orcástegui Gros, ed). Zaragoza 1986, p. 38. 
proponemos para la escultura de San Zoilo, es inevitable preguntarse si la importación a Tierra de Campos y sus aledaños se hizo desde Loarre a través de la desaparecida portada septentrional de la iglesia del antiguo priorato cluniacense. Sin duda el edificio más ambicioso de Carrión era este y no parece sino obvio que algunos de sus rasgos tipológicos irradiaran a las renovadas iglesias de la población y del área geográfica ${ }^{29}$.

Regresando a la iglesia de Loarre, su cronología ha sido fundamentada en dos fuentes que, en cualquier caso, indican referencias relativas: una ambigua noticia de la Crónica de San Juan de la Peña de $1094{ }^{30}$ y un epígrafe funerario fechado en 1096 y situado en la jamba derecha de su portada meridional ${ }^{31}$. En la actualidad y considerando ambas datas no parece haber divergencias en ubicar la cronología relativa de este edificio en el entorno de 1100 dentro de la órbita de la catedral de Jaca ${ }^{32}$. Evitando lo temerario que supone acotar una cronología en exceso estrecha sin aval documental y teniendo en cuenta que del edificio solo han subsistido representativos jirones, este mismo tramo cronológico fue propuesto hace algunos años para el templo de San Zoilo.

El nuevo hito escultórico aparecido en la iglesia de San Zoilo de Carrión de los Condes pone una vez más de relieve la dinámica alcanzada durante el desarrollo del románico pleno por el eje que transitaba desde las estribaciones de los Pirineos hacia el extremo noroeste de la Península a través de esa arteria que, vertebrando los reinos por los que discurría, remataba en el sepulcro del Apóstol Santiago. Como ha puesto de relieve el estudio de edificios como las catedrales de Jaca y Compostela o las iglesias de San Martín de Frómista y de San Isidoro de León, en un momento de febril renovación arquitectónica como el acontecido en el entorno del cambio de los siglos XI y XII, el trasvase de canteros y escultores de una fábrica a otra supuso un fenómeno que, ante la pérdida de algunos significados edificios, está aún por cuantificar ${ }^{33}$.

José Luis Senra Gabriel y Galán Universidad de Santiago de Compostela

\footnotetext{
${ }^{31}$ Ante la rotundidad de criterio de Kingsley Porter a la hora de considerarlo un terminus ante quem (Arthur K. Porter: La escultura románica en España. Barcelona 1930 (Firenze/Paris 1928), vol. I, p. 80), y en un momento en el que las tesis cronológicas del historiador del arte norteamericano eran aún objeto de duras arremetidas, Georges Gaillard ya advirtió sobre la cautela que exigía ya que, para él, bien pudiera provenir de una construcción anterior y haber sido reutilizada (Gaillard (1938): 134). Sin embargo, aún contemplando la posibilidad de un reaprovechamiento, no hay dificultad alguna en compatibilizar la data de este epígrafe y el edificio en que se inserta.

${ }^{32}$ Gómez Moreno (1934): 79; Walter M. Whitehill: Spanish Romanesque Architecture of the Eleventh Century, Oxford 1968 (1941), pp. 249-250. Más recientemente: Katherine Watson: «The Corbels in the Dome of Loarre», Journal of the Warburg and Courtauld Institutes, XLI (1978), pp. 297-298; Mann (1991): 94; Antonio Durán Gudiol: El castillo de Loarre y sus alrededores, Huesca 1987, p. 60; María del Carmen Lacarra Ducay: Catedral y Museo diocesano de Jaca, Gante 1993, pp. 15-16.

${ }^{33}$ Lamentablemente, huérfanos de excavaciones arqueológicas, seguimos teniendo un conocimiento muy sumario de conjuntos monásticos tan representativos como el de Santa María de Nájera o el de San Benito de Sahagún.
} 